\title{
PSIKOEDUKASI AGRESI SEBAGAI UPAYA UNTUK MENINGKATKAN PENGETAHUAN ANTI AGRESI PADA SISWA SMPN ABC SURABAYA
}

\author{
Daniel Reyonald Bungaran* \\ Ika Yuniar Cahyanti** \\ *Universitas Airlangga \\ **Universitas Airlangga
}

DOI: https://doi.org/10.21009/JPPP.091.02

\author{
Alamat Korespondensi: \\ danielrbslydiah@gmail.com
}

\begin{abstract}
This psychological intervention aims to increase the knowledge of anti-aggression among students in class " $X$ ", SMPN ABC, Surabaya by giving anti-aggression psychoeducation. This research is a pre experimental research, one group pretest- posttest design. Whole sampling was used as sampling technique with 39 students as sample. The knowledge of anti-aggression was measured by pretest-posttest questionnaire made by researcher. Data is analyzed by using paired sample t-test. The result of intervention shows that there is a significant difference between pretest and posttest score of knowledge of anti-aggression $(p=0.000<0.05)$ after the delivery of psychoeducation.
\end{abstract}

Keywords

anti-aggression, psychoeducation, social skill, junior high school

\section{Pendahuluan}

Permasalahan perilaku remaja sering menjadi tema tahunan yang muncul di media cetak maupun elektronik. Berbagai perilaku yang sering ditunjukkan adalah menampakkan sikap permusuhan dan kemarahan, merusak fasilitas umum, perkelahian, tawuran dan perilaku lainnya dengan variasi kasus yang semakin beragam. Keberagaman perilaku yang dilakukan remaja beserta penyimpangannya sering kali menuai keheranan dari generasi sebelumnya. Indikasi kesulitan dalam memahami perilaku remaja masa kini diwarnai dengan berbagai istilah, antara lain memberikan predikat "generasi jaman now" kepada mereka.

Remaja merupakan kelompok berisiko mengalami permasalahan perilaku. Masa remaja adalah masa peralihan perkembangan yang berlangsung sejak usia sekitar 10 atau 11 tahun atau bahkan lebih awal, dan berlangsung hingga masa remaja akhir yang melibatkan perubahan besar dalam aspek fisik, kognitif dan psikososial yang saling berkaitan (Papalia, Olds \& Feldman, 2009). Pada masa peralihan tersebut terdapat banyak perubahan gaya hidup yang biasanya mengakibatkan kemungkinan munculnya perilaku berisiko menjadi lebih tinggi dibandingkan dengan kelompok usia lainnya di masyarakat. Masa remaja juga merupakan masa pencarian jati diri sehinga remaja memiliki rasa ingin tahu yang tinggi untuk melakukan hal-hal baru yang belum pernah dilakukan sebelumnya. Rasa ingin tahu yang tinggi tersebut membuat remaja sering melakukan penyimpangan perilaku seperti menggunakan obatobatan terlarang, minum-minuman keras, seks bebas dan lain-lain. Dalam The Youth Risk Behavior Surveillance System, disebutkan bahwa beberapa perilaku berisiko tersebut merupakan

Jurnal Penelitian dan Pengukuran Psikologi, Vol. 9 , 1 , April 2020 
perilaku yang sangat sering dilakukan oleh remaja (Hurlock, 2005).

Permasalahan perilaku juga terjadi pada remaja di lingkungan SMPN ABC Surabaya yang merupakan salah satu sekolah binaan Puskesmas Keputih, yang terletak di daerah Medokan Semampir, Sukolilo, Surabaya. Sekolah Menengah Pertama ini memiliki visi beriman dan bertaqwa, cerdas, beretika, unggul dalam prestasi, kompetitif, dan berwawasan lingkungan. Misi sekolah ini yakni mewujudkan pendidikan yang menghasilkan lulusan cerdas, terampil, beriman, bertaqwa, dan memiliki keunggulan kompetitif. Sekolah ini berstatus negeri di bawah kepemilikan pemerintah daerah. SMPN ABC Surabaya memiliki luas sekitar 2324 meter persegi dengan peserta didik sebanyak 826 siswa yang terdiri dari 439 siswa laki-laki dan 387 siswa perempuan (Kementerian Pendidikan dan Kebudayaan, 2018).

Secara khusus, permasalahan perilaku yang disorot adalah perilaku agresivitas yang sering dimunculkan oleh para siswa SMPN ABC, khususnya kelas IX. Menurut Sukmadinata (2007), perilaku agresif dapat dikategorikan sebagai bentuk ekspresi emosional yang biasanya muncul karena ketidakmampuan individu dalam mengelola emosi dan menyesuaikan diri dengan lingkungannya, yang diwujudkan dalam bentuk perilaku agresif atau penarikan diri. Agresivitas seseorang merupakan kesalahan dalam penyesuaian diri, berbentuk kenakalan, kebrutalan, kekerasan dan kemarahan.

Penggalian data awal yang dilakukan dengan menggunakan kuesioner analisa kebutuhan yang telah disebar oleh pemeriksa kepada siswa-siswa dari salah satu kelas IX mendapatkan hasil bahwa sebanyak 27 dari 41 siswa pernah merasakan tersakiti akibat omongan yang tidak baik dari temannya. Omongan tersebut bisa berupa hinaan, panggilan yang menyakitkan hati, cemoohan, dan sebagainya.

Di samping itu, wawancara dengan Ibu $\mathrm{H}$, guru agama, dan Ibu I, guru bimbingan konseling, juga menguatkan kesimpulan awal bahwa sebagian siswa kelas IX berperilaku agresif. Beberapa perilaku tersebut adalah mencoret-coret dinding sekolah dengan gambar alat kelamin, berbicara kasar, sikap mengganggu pelajaran di kelas dan sikap premanisme. Sikap premanisme yang dimaksud adalah aktivitas yang dilakukan secara berkelompok dan menyatakan kuasa serta kekuatan fisik atas siswa dari kelas-kelas lain. Selain itu juga diketahui bahwa sebagian siswa dalam kehidupan mereka di luar sekolah pernah terlibat dalam minuman keras, merokok, narkoba dan menghabiskan waktu yang lama di "warnet".

Menanggapi tantangan dalam mengajar di sekolah tersebut, kedua guru di atas juga menyatakan bahwa selain harus memiliki kecakapan dalam mengajar, untuk dapat bertahan secara mental dalam melakukan tugas-tugas sebagai guru di sekolah tersebut, mereka merasa harus memiliki kemampuan bernegosiasi dengan murid, kecakapan dalam berkomunikasi dan wibawa yang besar agar didengar oleh murid-murid. Mengomentari kemampuan guru-guru dalam berhadapan dengan kenakalan siswa, Ibu H berkata: "Banyak guru-guru di sekolah ini merasa rendah diri bagaikan singa yang tidak bertaring dalam menghadapi kenakalan murid-murid." Selanjutnya menurut mereka, murid-murid cenderung tidak mendengarkan nasihat mereka. Di sisi lain, orang tua merasa kewalahan terhadap anak-anak mereka sendiri. Bila guru wali kelas melaporkan perilaku anaknya kepada orang tua, guru-guru akan mendapatkan respon negatif, antara lain seperti meminta guru untuk memukul anak mereka agar jera. Di samping itu, guru-guru juga menerima masukan dari orang tua murid bahwa siswa sering pergi dari rumah selama beberapa waktu bila orang tua mereka memarahi atau menasihati mereka.

Bila uraian di atas ditelaah dari teori kontekstual ekologis yang disampaikan oleh Bronfenbrenner (dalam Santrock, 2007), maka perilaku agresi siswa setidaknya terkait dengan tiga sistem dalam teori tersebut. Pertama, mikrosistem. Dalam sistem ini, perilaku agresi hadir dalam interaksi dengan sesama siswa. Sebagian perilaku tersebut diimitasi dari kakak kelas dan berkembang dengan adanya dinamika interaksi antar siswa. Keadaan ini diperkuat dengan kebiasaan menghabiskan waktu sepulang sekolah secara bersama-sama, baik di warung internet maupun di warung kopi. Menurut ZH, salah satu wali kelas IX, lingkungan tempat tinggal yang tidak sehat serta padatnya penduduk juga memicu timbulnya masalah yang beragam. Masalah-masalah seperti kekerasan dalam rumah tangga, premanisme, kekerasan fisik dan verbal merupakan permasalahan yang sering terjadi. Keadaan ini tentunya mempengaruhi perkembangan anak sehingga anak menjadi sangat mudah belajar dan 
meniru perilaku agresi dari lingkungan sekitarnya.

Kedua, mesosistem. Pada sistem ini, belum ada sinergi antara orangtua siswa dan pihak sekolah. Bila pihak sekolah mengundang orangtua siswa untuk membahas perilaku agresi siswa, kebanyakan orangtua menolaknya dan melempar tanggung jawab sepenuhnya kepada sekolah. Di sisi lain, pihak guru sudah merasa kewalahan dengan perilaku agresi siswa dan cenderung menghindari permasalahan tersebut dengan hanya berfokus pada tugas memberikan materi pelajaran. Ketiga, ekosistem. Dalam sistem ini, kesibukan orangtua yang kebanyakan berasal dari keadaan ekonomi menengah ke bawah, mempengaruhi pola interaksi mereka dengan anak sehingga orangtua kurang memberi pengawasan terhadap perilaku anak.

Langkah pertama untuk menekan perilaku agresi siswa adalah dengan memberikan psikoedukasi agresi. Program intervensi komunitas ini lebih difokuskan pada usaha yang dapat membuka wawasan siswa mengenai pengetahuan tentang kontrol sosial yang dapat menghasilkan peningkatan dalam segi moral dan tanggung jawab terhadap standar budaya. Pendekatan yang paling mendekati permasalahan siswa kelas IX tersebut adalah pengetahuan tentang keterampilan sosial. Dasar-dasar dalam pemberian pelatihan keterampilan sosial ini adalah mengajarkan dan memberi wawasan siswa tentang kemampuan untuk berbagi, saling membantu, meminta tolong dan memiliki inisiatif dalam konteks sosial. Hosteter dan Miller (2000) menulis bahwa individu yang memiliki keterampilan sosial kurang, akan memiliki masalah yang berhubungan dengan pekerjaan, kesehatan fisik, kesehatan mental, hubungan sosial dan kualitas hidup.

\section{Metode Penelitian}

Psikoedukasi ini menggunakan jenis penelitian eksperimen dengan metode kuantitatif. Desain penelitian eksperimen yang digunakan dalam penelitian ini adalah pra-eksperimen, yakni one group pretest-posttest. Metode ini menggunakan satu kelompok yang diberikan alat ukur sebelum dan setelah diadakannya intervensi. Alat ukur yang digunakan dalam penelitian ini adalah alat ukur mengenai pengetahuan anti agresi yang telah penulis susun sebelumnya.

Intervensi ini menggunakan pendekatan kognitif behavior. Intervensi dengan pendekatan kognitif behavior tidak hanya bertujuan untuk mengubah penilaian individu terhadap pikiran, perasaan dan perilakunya namun juga memodifikasi perilaku (Seligman \& Reichenberg, 2010).

Teknik pengambilan sampel menggunakan teknik sampling whole sampling dimana responden dalam penelitian ini merupakan keseluruhan siswa kelas "X" di SMP ABC Surabaya. Alasan peneliti memilih kelas " $X$ " adalah karena menurut penuturan guru agama dan guru BK, siswa pada kelas tersebut menunjukkan perilaku agresi tertinggi dibandingkan kelas lainnya. Subjek penelitian dalam penelitian ini berusia 14-15 tahun. Selain itu, teknik analisa data yang digunakan dalam penelitian ini menggunakan uji parametrik yakni paired sample t-test.

\section{Hasil Penelitian dan Diskusi}

Subjek penelitian ini berjumlah 39 orang dengan jumlah laki-laki 17 orang (43\%) dan jumlah perempuan 22 orang $(57 \%)$. Berikut akan ditampilkan mengenai perbedaan skor pengetahuan pada saat sebelum dan setelah intervensi dilakukan.

Tabel 1. Distribusi Subjek Penelitian

\begin{tabular}{cccc}
\hline Subjek & Jenis Kelamin & Pre test & Post test \\
\hline 1 & $\mathrm{P}$ & 5 & 8 \\
\hline 2 & $\mathrm{P}$ & 6 & 11 \\
\hline 3 & $\mathrm{~L}$ & 6 & 13 \\
\hline 4 & $\mathrm{~L}$ & 8 & 13 \\
\hline 5 & $\mathrm{~L}$ & 6 & 10 \\
\hline 6 & $\mathrm{P}$ & 7 & 10 \\
\hline 7 & $\mathrm{~L}$ & 5 & 6 \\
\hline 8 & $\mathrm{P}$ & 5 & 9 \\
\hline
\end{tabular}

Jurnal Penelitian dan Pengukuran Psikologi, Vol. 9 , 1 , April 2020 
Daniel Reyonald Bungaran Ika Yuniar Cahyanti
Psikoedukasi Agresi Sebagai Upaya Untuk Meningkatkan Pengetahuan Anti Agresi Pada Siswa SMPN ABC Surabaya

\begin{tabular}{|c|c|c|c|}
\hline 9 & $\mathrm{P}$ & 7 & 10 \\
\hline 10 & $\mathrm{P}$ & 5 & 11 \\
\hline 11 & $\mathrm{P}$ & 6 & 9 \\
\hline 12 & $\mathrm{P}$ & 4 & 7 \\
\hline 13 & $\mathrm{P}$ & 3 & 10 \\
\hline 14 & $\mathrm{P}$ & 7 & 11 \\
\hline 15 & $\mathrm{P}$ & 6 & 7 \\
\hline 16 & $\mathrm{P}$ & 2 & 5 \\
\hline 17 & $\mathrm{P}$ & 5 & 8 \\
\hline 18 & $\mathrm{P}$ & 6 & 12 \\
\hline 19 & $\mathrm{~L}$ & 4 & 14 \\
\hline 20 & $\mathrm{~L}$ & 6 & 9 \\
\hline 21 & $\mathrm{P}$ & 5 & 12 \\
\hline 22 & $\mathrm{~L}$ & 3 & 11 \\
\hline 23 & $\mathrm{~L}$ & 6 & 13 \\
\hline 24 & $\mathrm{P}$ & 2 & 6 \\
\hline 25 & $\mathrm{~L}$ & 3 & 13 \\
\hline 26 & $\mathrm{~L}$ & 6 & 9 \\
\hline 27 & $\mathrm{~L}$ & 4 & 9 \\
\hline 28 & $\mathrm{~L}$ & 6 & 13 \\
\hline 29 & $\mathrm{~L}$ & 5 & 5 \\
\hline 30 & $\mathrm{~L}$ & 3 & 7 \\
\hline 31 & $\mathrm{~L}$ & 5 & 10 \\
\hline 32 & $\mathrm{~L}$ & 8 & 14 \\
\hline 33 & $\mathrm{P}$ & 7 & 12 \\
\hline 34 & $\mathrm{P}$ & 7 & 12 \\
\hline 35 & $\mathrm{P}$ & 7 & 13 \\
\hline 36 & $\mathrm{P}$ & 10 & 15 \\
\hline 37 & $\mathrm{~L}$ & 4 & 6 \\
\hline 38 & $\mathrm{P}$ & 8 & 8 \\
\hline 39 & $\mathrm{P}$ & 7 & 11 \\
\hline
\end{tabular}

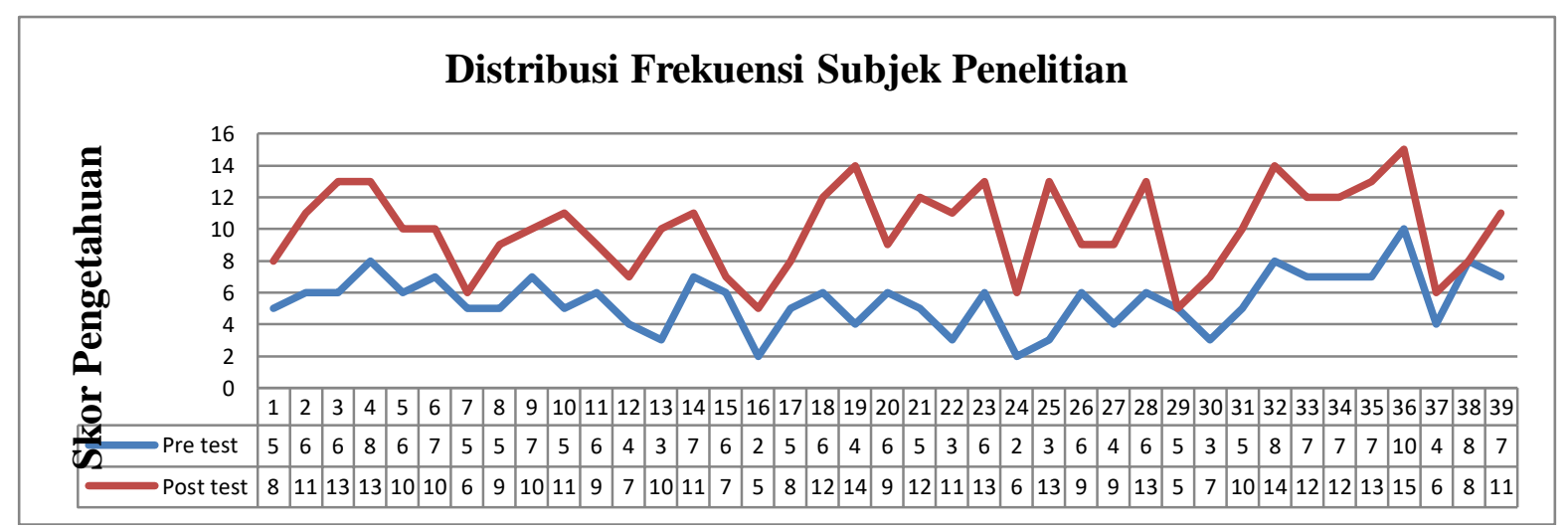

Gambar 1. Distribusi Frekuensi Subjek Penelitian 
Daniel Reyonald Bungaran

Ika Yuniar Cahyanti
Psikoedukasi Agresi Sebagai Upaya Untuk Meningkatkan Pengetahuan Anti Agresi Pada Siswa SMPN ABC Surabaya

Sebelum melakukan uji hipotesis, peneliti juga

melakukan uji asumsi yakni uji normalitas.

Tabel 2. Hasil Uji Normalitas

\begin{tabular}{ccc}
\hline & Pre-test & Post-test \\
\hline Skewness & -.022 & -.204 \\
Kurtosis & -.088 & .861 \\
\hline
\end{tabular}

Normalitas data dapat dilihat dari nilai skewness dan kurtosis. Data tergolong normal jika memiliki nilai skewness yang bergerak dari -1 sampai 1 dan nilai kurtosis dalam rentang -2 sampai 2. Hal ini dapat dikatakan bahwa data untuk pretest dan posttest tergolong normal.

Hasil uji normalitas menunjukkan bahwa status sebaran data normal. Hal inilah yang membuat peneliti menggunakan teknik parametrik yakni paired sample t-test.

Tabel 3. Hasil Uji Hipotesis

\begin{tabular}{cccccc}
\hline & Mean & SD & t & df & Sig. \\
\hline $\begin{array}{l}\text { Pretest- } \\
\text { Posttest }\end{array}$ & -.453 & 2.33 & -12.1 & 38 & .000 \\
\hline
\end{tabular}

Berdasarkan tabel di atas, dapat diketahui bahwa nilai signifikansi berdasar paired sample $t$ test yang diperoleh adalah sebesar $0.000(<0.05)$. Hal ini menunjukkan bahwa terdapat perbedaan pengetahuan peserta sebelum dan sesudah diberikan pelatihan. Dengan kata lain, pelatihan yang diberikan membawa pengaruh yang signifikan pada perubahan pengetahuan siswa.

Adanya pengetahuan mengenai keterampilan sosial dapat membuat individu menunjukkan perilaku tersebut. Individu yang memahami keterampilan sosial akan lebih dapat mengaplikasikan keterampilan sosial dibandingkan individu yang tidak memiliki pengetahuan tersebut. Sejalan dengan yang dikatakan oleh Azwar (2013) bahwa tidak adanya pengetahuan mengenai suatu hal akan membuat individu tidak menunjukkan perilaku sesuai dengan pengetahuan tersebut. Sebaliknya, jika individu memiliki pengetahuan mengenai suatu hal maka individu tersebut akan cenderung menunjukkan perilaku yang sejalan.

Pengetahuan merupakan domain yang sangat penting untuk terbentuknya sebuah perilaku. Perilaku yang didasari oleh pengetahuan akan bertahan lebih lama dibandingkan perilaku yang tidak didasarkan pada pengetahuan (Notoatmodjo dalam Febriani, Samino \& Sari, 2016). Dengan demikian, pemahaman peserta mengenai keterampilan sosial yang telah diperoleh melalui pelatihan ini akan berkontribusi terhadap kemampuan peserta untuk melakukan keterampilan sosial dalam kehidupan sehari-hari.

\section{Kesimpulan}

Hasil analisis menunjukan bahwa program pelatihan keterampilan sosial dan perilaku anti agresi yang dilakukan dalam intervensi memberikan pengaruh dalam meningkatkan pengetahuan anggota komunitas tentang keterampilan sosial. Intervensi yang telah dilakukan juga memberikan pengetahuan baru kepada anggota komunitas tentang teknik komunikasi untuk berelasi dengan orang lain secara baik dan benar.

\section{Daftar Pustaka}

Azwar, S. (2013). Sikap manusia: teori dan pengukurannya. Yogyakarta: Pustaka Pelajar.

Febriani, Samino \& Sari (2016). Faktor yang Mempengaruhi Perubahan Perilaku BABS. Jurnal Dunia Kesmas 5, 121-130, 2016.

Hosteter, C., \& Miller, D. (2000). Teaching skill for life. Special Educator, 20, 5-10. 
Hurlock, E. B. (2005). Psikologi perkembangan: Suatu pendekatan sepanjang rentang kehidupan. Jakarta: Penerbit Erlangga.

Kementrian Pendidikan dan Kebudayaan. (2015). Data pokok pendidikan dasar dan menengah direktorat jenderal pendidikan dasar dan menengah: SMP Negeri 52. Diunduh dari http://dapo.dikdasmen.kemdikbud.go.id/se kolah/351320D4C99C 629FF74C.

Papalia, Diane E., Olds, S.W., \& Feldman, R.D.. (2009). Human development. New York: McGraw-Hill Higher Education.
Santrock, J.W. (2007). Life span development. New York: McGraw-Hill Companies.

Selligman, L. \& Reichenberg, L.W. (2010). Theories of counseling and psychotherapy. $3^{\text {rd }}$ edition. USA: Pearson.

Sukmadinata, N.(2007). Bimbingan dan konseling dalam praktek. Bandung: Maestro 